\title{
Analysis on Electrification Development Mode from a Global Perspective
}

\author{
J unshu Feng ${ }^{1, *}$ and Peng Wang ${ }^{1}$ \\ ${ }^{1}$ State G rid Energy Research Institute Co., Itd, Changping, B eijing, China
}

\begin{abstract}
In the context of a global response to climate change, the key to the future low-carbon energy transition is "electricity-cantered", which makes use of renewable energy. This paper studied the typical modes of improving electrification from a global perspective, including clean energy driving mode, industry upgrading driving mode, regional resource integrated planning mode, power grid-led mode and inclusive mode for all. The research can provide options of electrification development in different regions all over the world.
\end{abstract}

\section{Introduction}

In the context of global response to climate change, realization of clean and low-carbon energy development is the strategic choice of energy transition [1] of all countries. Owing to the limited resources of hydrocarbon and carbon fossil energy, the key to the future lowcarbon energy transition is "electricity-cantered", which makes use of green energy at the side of energy production and improves the electrification level at the side of energy consumption [2-3].

This paper intends to study the typical modes of improving electrification from a global perspective, propose the typical modes of improving electrification in major regions and provide options of electrification development in different regions all over the world.

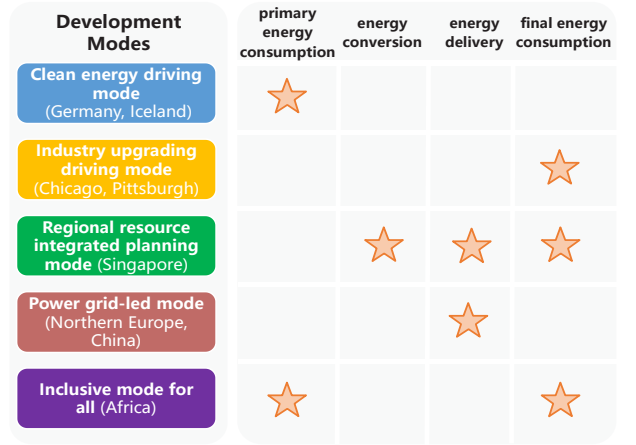

Fig. 1. Typical modes of electrification improvement

\section{Overview}

B ased upon the major factors influencing electrification, the practical experience of electrification development in major countries has been sorted out and summarized and in terms of the full energy chain such as the links of energy production, processing and conversion, transmission, consumption, etc.
There are five development modes of electrification around the world, as shown in Figure 1. They are the clean energy driving mode of primary energy production link represented by Germany and Iceland, the industry upgrading driving mode of final energy use link represented by Chicago and Pittsburgh, the regional resource integrated planning mode focusing on backend link represented by Singapore, the power grid-led mode of energy transmission link represented by North Europe and China, and the inclusive mode for all that focuses on both primary energy production and final energy use represented by A frica.

\section{Analysis of five electrification development modes}

\subsection{Clean energy driving mode}

The clean energy driving mode means that the local abundant clean energy such as hydro, wind and solar energy is turned into electricity for use so as to support the economy and urban development by green electricity, i.e. to drive the growth of final electrification by clean energy supply, as shown in Figure 2.

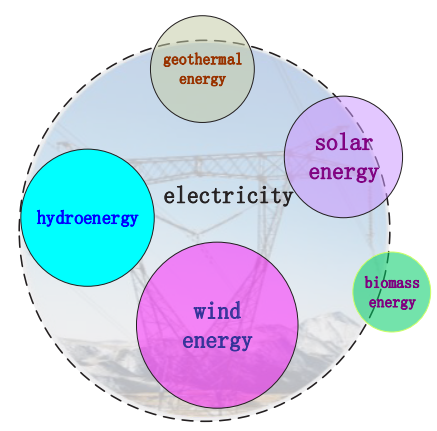

Fig. 2. Clean energy driving mode

\footnotetext{
${ }^{*}$ Corresponding author: fengjunshu@ sgeri.sgcc.com.cn
} 
With the renewable energy such as wind and solar energy as the supplier, this mode is based upon the local resource and clean energy endowment to realize electricity alternative in many links. The clean electricity is utilized in activities of mining, industrial production and processing, foreign trade, etc. to cultivate a virtuous cycle of energy and electricity, resource exploitation, industrial processing and manufacturing, trade, etc. and break their barriers to spur the potentials. Such mode gives full play to the interactive benefits and empowers economy development by creating pillar industry and new prime mover which can fundamentally change the models of energy development and economy development and thus guarantee the socioeconomic sustainability.

For example, as shown in Figure 3, Germany stands on the local resources and clean energy endowment and strongly promotes the electrification development mode based on the energy supplier of renewable energy such as wind and solar energy, thus achieving steady progress of electrification level. According to International Energy A gency (IEA), from 2000 to 2018, the country experienced booming development of renewable energy especially the new energy where the wind power increased from 7.5TWh to 111.5TWh, the biomass power soared from 2.9TWh to 51.3TWh and the solar power rocketed from 0.1TW $\mathrm{h}$ to $46.2 \mathrm{TWh}$. A ccording in 2015, the final electrification level in Germany registered $20.1 \%$ with an increase of about $2.1 \%$ over the past 15 years.

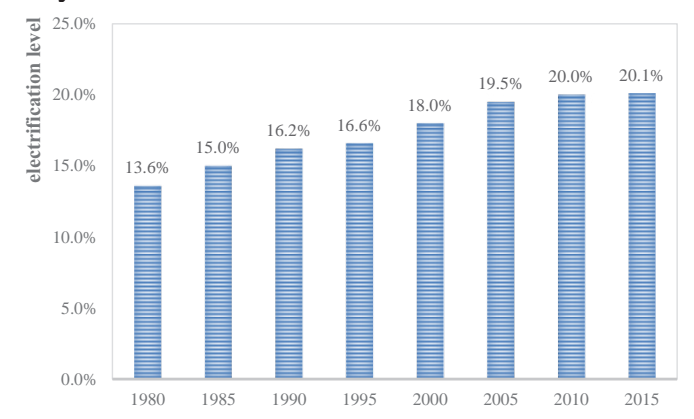

Fig. 3. German el ectrification levels (D ata source: IEA)

\subsection{Regional resource integrated planning mode}

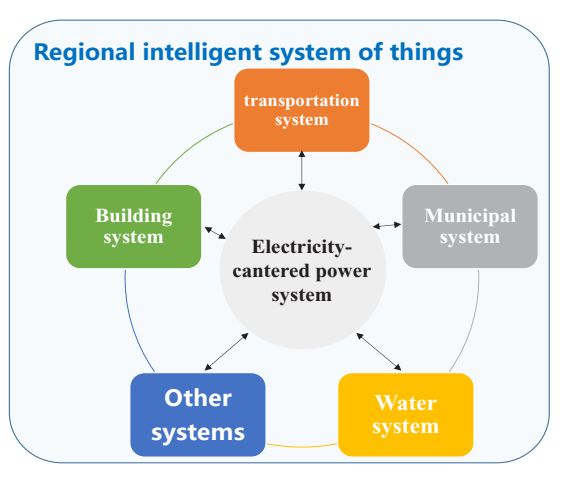

Fig. 4. Regional resource integrated planning mode

The regional resource integrated planning mode refers to the utilization of electricity characteristics such as extensive connection, intelligent control, etc. to advance the integration of regional energy and power system with other traffic, municipal, etc. systems in various aspects like infrastructure, control system, etc. so as to create an electricity-cantered regional smart Internet of Things of interconnection of all links and individuals, which yields more demand of electric energy, as shown in Figure 4.

The main characteristics of this mode are electricitycantered and grid-focused to propel electrification development. The regional energy supply is mainly for outbound transmission and the local energy production is relatively low. The electricity is featured with cleanness and efficiency, extensive application, convenient use, real-time controllability and flexible conversion. It has natural advantage of accommodating external clean energy and consuming local renewable energy, which provides ease of integration and interconnection with other energy systems; the electrification at energy use side can significantly uplift the social comprehensive energy efficiency and address the issue of urban environmental pollution; the regional grid enjoys the strength of resilient and flexible network, stable and reliable equipment and well-proven operation and management, which is an inevitable choice to guarantee the efficiency and safety of regional energy use.

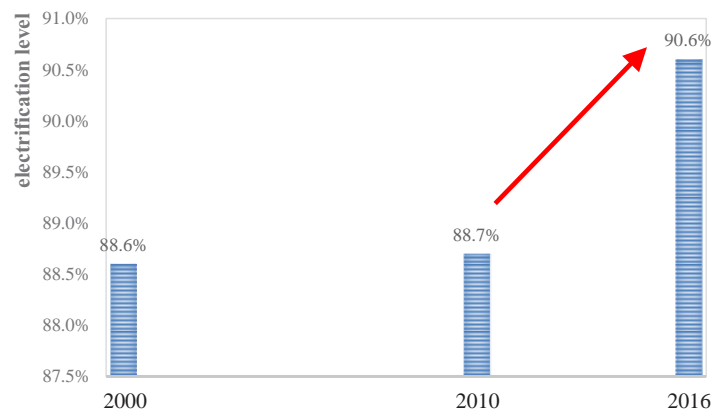

Fig. 5. Electrification levels of commercial and residential sectors in Singapore (D ata source: IEA)

For example, as shown in Figure 5, by cultivation of urban energy system, Singapore pushes forward the electricity-cantered comprehensive urban energy utilization and realizes multi-energy supplementation and coordinated operation. Singapore successfully keeps uplifting energy utilization efficiency and sustains a high level of final electrification level. From 2000 to 2016, the final electrification levels of commercial and residential sectors in this country were sustained around $90 \%$ and recorded $90.6 \%$ in 2016 . The growth pace is apparently faster than that of 2000-2010 period.

The construction of urban informatization facilities on the platform of "Smart Nation" boosts the consumption of electric energy. In June 2006, the Government of Singapore initiated the overall planning of "Smart Nation 2015" to form a platform of Smart Nation that targeted at an infrastructure and operation system of whole-island data collection, connection and analysis, on the basis of which to forecast the citizens $\odot$ demand and then provide better public services; it can foresee the roads of traffic jam, uses electronic eyes to monitor environment cleanness, arrange unmanned vehicles for short-range transport service, etc. All the 
relevant measures of building a smart city help improve the electrification level.

\subsection{Industry upgrading driving mode}

The industry upgrading driving mode means that as the human society enters the digital era with clear informatization characteristics, the industrialization is transforming and upgrading towards the informatization carried by electric energy, and the emerging new models and industry norms of social production keep enlarging the demand of electric energy, as shown in Figure 6.

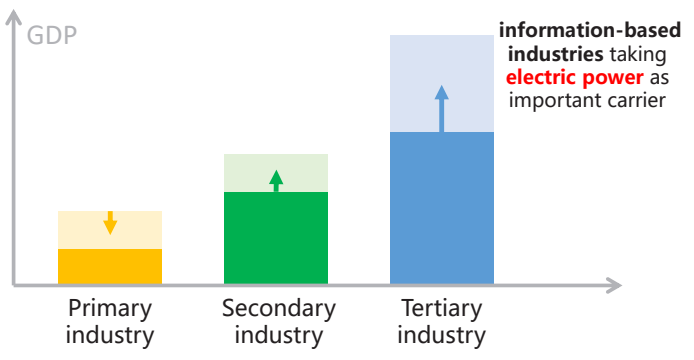

Fig. 6. Industry upgrading driving mode

Under this mode the industrial structure shifts from energy-intensified type to technology-intensified type while the electrification-based industrial structure keeps upgrading. With the standpoint of industry restructuring brought forth by economy development, driven by the evolution of industrialization process and the impact of the fourth industry revolution, the human society has presently stepped into a digital era. In this grand transformation period of prominent informatization characteristics, a few post-industrialization countries or cities are moving towards the industry structure mainly driven by informatization industry. The development of Big Data, Cloud, IOT and Mobile technologies heavily depends on electric energy and thus the new models and industry norms of social production yield swelling demand of electric energy.

For example, Chicago actively promotes the hightech industry transition to promote its own electrification development. As the American industry restructuring goes on, the original heavy-industry-cantered mode of Chicago is no longer sustainable. Therefore, the municipal government adopts various countermeasures of diversity for industry restructuring, transforming and upgrading. It should be noted that $\mathrm{Chi}$ cago endeavours to introduce the departments of emerging high-tech industry at the high end of value chain such as management, research \& development, marketing, etc. For instance, Chicago government proactively offers B oeing with preferential conditions for its relocation of headquarter to this city.

\subsection{Power grid-led mode}

The power grid-led mode is to give full play to the scale effect of grand grid in extensively allocating and optimizing resources and make use of the grid connection benefits of grand grid so as to improve the supply stability and economic competitiveness of electricity in final energy and thus improve the electrification level, as shown in Figure 7.

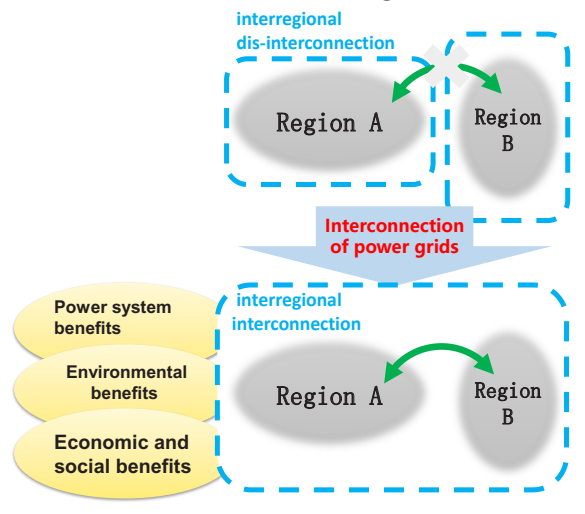

Fig. 7. Power grid-led mode

This mode gives full play to the grid capability of optimizing resource allocation and serving as a marketoriented platform to spur clean energy development and electric energy alternatives and generate the apparent interconnection benefits of grand grid [4]. The interconnection of grand grid can realize peak shaving and valley filling, multi-energy supplementation, mutual-standby effect of power system, uplift the utilization rate of system equipment, implement scale-up grid connection and development of cost-efficient renewable energy like wind and solar power, reduce emission of pollutants and GHG and effectively lower the final electricity price.

For example the North European grid consists of the grids of Norway, Sweden, Finland and the eastern grid of Denmark that are interconnected via HV AC/DC lines to form a joint electricity system of mutualsupplementary capacity and mutual standby sources. In addition, considering the national difference of main energy resources of power generation, the mutual supplementation of power output of multiple time scale has been achieved. Norway produces almost 100\% hydropower; Sweden has big shares of hydropower and nuclear power plus around $10 \%$ of wind power; Denmark has a large proportion of wind power that is followed by coal-fired power; Finland has a relatively balanced mix of power generation.

The expanding grid connection scale cuts down the tariff level on North European market. Thanks to the expansion of new energy development scale and improvement of market mechanism, the tariff level and energy use cost keep reducing. In the context of market competition, from 2007 to 2012 many European nations even permitted negative tariffs in their power market rules, which included the four nations joining the European Power Exchange (EPEX) namely France, Germany, Austria and Swiss plus North Europe, Belgium and the Netherlands.

\subsection{Inclusive mode for all}

The inclusive mode for all means that the regions where modern energy is hardly available or not affordable can benefit from the cost efficient renewable energy and 
well-established micro-grid technology to get affordable, convenient, safe and reliable power service by off-grid renewable energy system so as to attain the goal of modern energy access to all, as shown in Figure 8.

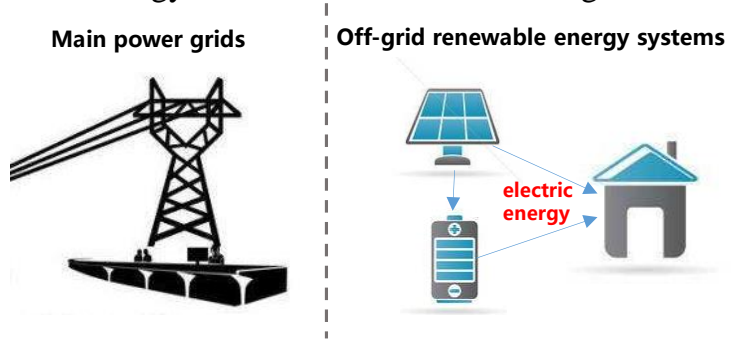

Fig. 8. Inclusive mode for all

For example there are currently 1.3 billion people around the world with no access to modern energy especially in Africa so that the goal of future energy development is to facilitate their access to energy. International Renewable Energy A gency (IRENA)'s report Off-grid Renewable Energy Solutions: Global and Regional Status and Trends points out that the off-grid renewable energy has turned out to be a mainstream solution of modern energy service in a society of sustainability [5]. From 2008 to 2017, the accumulative installed capacity of off-grid renewable energy in A frica soared from $231 \mathrm{M} \mathrm{W}$ to $1,200 \mathrm{M} \mathrm{W}$.

\section{Suggestions on electrification development modes in major regions}

\subsection{North America and Europe}

The developed nations in North A merica and Europe should enhance the industry upgrading driving mode and power grid-led mode. On one hand help the conventional industry system turn to a modernized intelligent industry system, and strongly promote and extensively apply the electrified intelligent manufacturing equipment in the qualified areas to replace conventional manufacturing equipment. On the other hand reinforce the upgrading and transformation of regional grids and develop the facilitating energy use segments like e-vehicles. It is expected that, after 2030, electric vehicles will have overwhelming advantages of cost efficiency and environmental friendliness and thus become the prioritized option to buyers.

\subsection{Asia, South America and Oceania}

Since Asia, South America and Oceania are three densely populated continents, regional resource integrated planning mode can better and more intensively satisfy the diversified demand of mass people. In the near term, they are to promote upgrading of urban energy management for urban energy development; in the mid- and long term, the comprehensive urban energy utilization should be advanced in a diversified and scaleup manner. In the sectors of urban industry, architecture, transport and lifestyle, the innovative application and popularization of energy transition technologies and models will improve the overall energy efficiency level and smart energy use level.

\subsection{Africa}

Given the abundant clean energy resources, A frica may push forward the energy access efforts and adopt the clean energy driving mode. For example, considering the interactive model of "electricity - mining - metallurgy industry - trade", which is to plan and build clean energy bases like hydropower plants, mining and metallurgy bases and industry parks as a whole, and form a power market of combined generation, transmission and consumption and integrated development pattern of mining, metallurgy and deep processing so as to effectively solve the problem of "lack of electricity for industry development and lack of market for electricity development".

\section{Conclusions}

This paper proposed five typical development modes of electrification around the world, including clean energy driving mode, industry upgrading driving mode, regional resource integrated planning mode, power grid-led mode and inclusive mode for all. In the future, developed countries in North A merica and Europe could enhance industry upgrading driving mode and power grid-led mode, regional resource integrated planning mode would be a good choice for A sia, South A merica and Oceania, and $A$ frica could adopt clean energy driving mode.

\section{Acknowledgement}

This work was supported by State Grid Corporation's Technological Project of China (Strategic planning and market mechanism research on energy green transition with re-electrification as the core, SGNY 0000N GJ S1800173).

\section{References}

1. T. Zhu, L. Wang. National Energy Transition (Zhangjiang U niversity Press, Hangzhou, 2015)

2. Y.Z. Zhang. An important sign of urban energy transformation - continuous upgrading of electrification level. Energy Review. 2017, 9(V 00): 29-31

3. X. Y in, J.S. Tan, Capital of Energy (CITIC Press Group, Beijing, 2019)

4. Q.L. Zhao, J.S. Feng, Y.M. Jin, etc. A ssessment of Environmental $B$ enefits under the Background of Global Energy Interconnection. Journal of Global Energy Interconnection, 2018, 1(sup.1): 257-262.

5. IRENA. Off-grid Renewable Energy Solutions, 2018. 